ACCEPTED MANUSCRIPT

\title{
The European master of science in nuclear fusion and engineering physics (FUSION-EP): 15 years of experience
}

To cite this article before publication: Guido Van Oost et al 2020 Eur. J. Phys. in press https://doi.org/10.1088/1361-6404/abc6e5

\section{Manuscript version: Accepted Manuscript}

Accepted Manuscript is "the version of the article accepted for publication including all changes made as a result of the peer review process, and which may also include the addition to the article by IOP Publishing of a header, an article ID, a cover sheet and/or an 'Accepted Manuscript' watermark, but excluding any other editing, typesetting or other changes made by IOP Publishing and/or its licensors"

This Accepted Manuscript is (C) 2020 European Physical Society.

During the embargo period (the 12 month period from the publication of the Version of Record of this article), the Accepted Manuscript is fully protected by copyright and cannot be reused or reposted elsewhere.

As the Version of Record of this article is going to be / has been published on a subscription basis, this Accepted Manuscript is available for reuse under a CC BY-NC-ND 3.0 licence after the 12 month embargo period.

After the embargo period, everyone is permitted to use copy and redistribute this article for non-commercial purposes only, provided that they adhere to all the terms of the licence https://creativecommons.org/licences/by-nc-nd/3.0

Although reasonable endeavours have been taken to obtain all necessary permissions from third parties to include their copyrighted content within this article, their full citation and copyright line may not be present in this Accepted Manuscript version. Before using any content from this article, please refer to the Version of Record on IOPscience once published for full citation and copyright details, as permissions will likely be required. All third party content is fully copyright protected, unless specifically stated otherwise in the figure caption in the Version of Record.

View the article online for updates and enhancements. 


\title{
The European Master of Science in Nuclear Fusion and Engineering Physics (FUSION-EP): 15 years of experience
}

\author{
Guido Van Oost ${ }^{1}$, Peter Beyer ${ }^{2}$, Alexis Devitre ${ }^{1}$, Rémy Guirlet ${ }^{3}$, Jean-Marie \\ Noterdaeme $^{4}$ and Hanne Thienpondt ${ }^{1}$
}

\author{
${ }^{1}$ Department of Applied Physics, Ghent University, Ghent, Belgium \\ ${ }^{2}$ Aix Marseille Université, CNRS, PIIM, UMR 7345, Marseille, France \\ ${ }^{3}$ CEA, IRFM, F-13108 Saint-Paul-lez-Durance, France \\ ${ }^{4}$ Department of Electrical Energy, Ghent University, Ghent, Belgium
}

E-mail : guido.vanoost@ugent.be

\begin{abstract}
The aim of the Erasmus Mundus Joint Master Degree (EMJMD) FUSION-EP is to provide a high-level research-oriented education and a well-integrated cultural experience within an international consortium of institutions leading the interdisciplinary field of magnetic fusion. The combined and harmonized teaching and research activities coordinated among eight partner universities in Belgium, Czech Republic, France, Germany and Spain offer a variety of competences in a field of crucial importance to the problem of world energy supply. Besides the ITER International Organization, there are $24 \mathrm{EU}$ and non-EU academic and research associate partners. As the fusion community makes pace towards commercialization, the balance in research will shift from an academic-and-fundamental direction to a technology-and-industry-driven orientation. For this purpose, the programme offers two tracks: fusion science and fusion engineering. In addition, an advisory board keeps the curriculum in line with the research activities carried out by the associate and industrial partners. Internationalization, multidisciplinarity, and student mobility are inherent parts of the programme structure and philosophy. There exist several student and alumni initiatives leveraging meaningful connections within a global network. As a first step towards long-term sustainability, the consortium decided to transfer the programme coordination from Ghent University to Aix-Marseille University in 2019; the geographical, topical and professional proximity of ITER is expected to allow an optimal alignment of the programme with the professional needs of the emerging nuclear fusion industry.
\end{abstract}

Keywords: Erasmus+ Programme, Erasmus Mundus Joint Master Degree, engineering physics, magnetic fusion, fusion technology, ITER, world energy supply

\section{Introduction, background and objectives}

The main focus of magnetic confinement fusion research worldwide and probably one of the most ambitious scientific collaborations of all times is the international tokamak ITER [1]. Its continuing mission is to complete our understanding of burning plasmas and prove the scientific and technical viability of controlled nuclear fusion power. As the fusion community progresses towards commercialization, research is shifting from a fundamental science orientation to an industry-driven technological approach exploiting a growing number of synergies with the nuclear fission sector i.e. the "nuclearisation of fusion"(see curriculum, section 2). This new stage is described and argued in the EUROfusion roadmap, which forms the European fusion programme and provides a clear and structured way forward to commercial electricity from fusion [2].

The Europeanization of higher education has gained considerable scope and momentum over the past quarter century, and the European higher education area (EHEA) has become a model for other regions. Whereas the coordinative Bologna process has facilitated standardization across countries, the European Commission (EC) funding programmes target universities more directly. The European Union (EU) has strengthened the scope of its influence across levels, supporting organizations to extend their cross-border activities not only in research but also in teaching [3]. 
EMJMD courses are joint study programmes delivered by a consortium of higher education institutions (HEls). The Erasmus Mundus Joint Degree Programme (below abbreviated as EM), is an incentive-based programme, and is organized, at present, under the Erasmus+ umbrella initiative managed by the EC and the education, audio-visual and culture executive agency (EACEA). It adds a more selective (and concentrated) layer of student mobility to the general development of the Erasmus+ programme. The EM was launched in 2004 to promote a 'prestigious, integrated, international study programme', and aims to support the development of quality European Master's degrees and to promote the visibility and attractiveness of European higher education in non-member countries. The keyword in EMJMDs is the notion jointness to describe the process of cooperation in the programme design and implementation in all stages : from devising an integrated course, through the development of joint and integrated management structures, the achievement of impact in terms of interinstitutional transfer of knowledge, the harmonization and recognition of awarded degrees and finally, to the integration of EM students in the local environment. Until 2013, the EM also included joint doctoral programmes (such as the doctoral college FUSION-DC), which then became integrated into the Marie Skłodowska-Curie Actions [3].

Funding programmes facilitate the EC's objectives of fostering pan-European networks in teaching across diverse academic fields, and impact and target universities more directly as they facilitate international networks, drive cross-border exchange, and establish novel transnational joint degrees that are jointly recognized, as a novel European feature in higher education. This new logic involves the creation of European university networks as a distinct layer in an increasingly interconnected, and nested, global higher education field, and undergirds European ideals of exchange and mobility and facilitates the construction of European identity in and through higher education [3].

The European master of science in nuclear fusion and engineering physics (FUSION-EP) is an international graduate studies programme, started in 2006, along with the decision to build ITER in Europe. Founded under the auspices of Erasmus Mundus [3], the FUSION-EP joint master's degree is offered by 8 core partner universities from Belgium, Czech Republic, France, Germany, and Spain, as well as 25 academic and research partners from the European Union, China, Russia, India, Ukraine, and the USA as well as the ITER international organization ITER IO), all listed below. An advisory board, including representatives from scientific, academic and industrial stakeholders, guarantees academic quality by assisting the steering committee (SC) of FUSION-EP in the student selection process, by suggesting updates to the teaching content and by advising the SC on the master's thesis topics proposed to the students. The advisory board enables a solid contact with industry and the proper consideration of employability needs (see section 3), thereby ensuring favourable prospects for longterm sustainability. The FUSION-EP joint master's degree is accompanied by a joint degree certificate, delivered with a diploma supplement describing the curriculum and the corresponding credits. This supplement can facilitate the readability of the degree, thus helping to promote its market value.

Core (full) and associate partners of the European master of science in nuclear fusion and engineering physics (FUSION-EP) are listed below (status in 2020).

\section{Core partners}

- Aix-Marseille Université (AMU), Marseille, France, coordinating institution

- Institut National des Sciences \& Techniques Nucléaires (INSTN), France

- Ghent University, Ghent, Belgium

- Universidad Complutense de Madrid (UCM), Madrid, Spain

- Universidad Carlos III de Madrid (UC3), Madrid, Spain

- Université de Lorraine, Nancy/Metz, France

- Universität Stuttgart, Stuttgart, Germany

- České vysoké učení technické v Praze (CzechTechnical University CVUT-CTU), Prague, Czech Republic

\section{Associate partners EU}

- Universidad de Sevilla (University of Sevilla), Spain

- Karlsruher Institut für Technologie (Karlsruhe Institute of Technology, KIT), Germany

- FuseNet Assocation

- Institute of Plasma Physics of the Czech Academy of Sciences (IPP.CR), Prague, Czech Republic

- $\quad$ Centrum Vyzkumu Rez (CV REZ), Prague, Czech Republic

- Centro de Investigaciones Energéticas, Medioambientales y Technológicas (CIEMAT), Madrid, Spain 
- Dutch Institute for Fundamental Energy Research (DIFFER-FOM), Netherlands

- Forschungszentrum Jülich, Germany

- Commissariat à l'Energie Atomique- Institute for Magnetic Confinement Research (CEA-IRFM), Cadarache, France

- Max-Planck-Institut für Plasmaphysik, Garching and Greifswald, Germany

- Technische Universiteit Eindhoven (Eindhoven University of Technology), Netherlands

- University of Padua,Italy

- Sofia University St. Kliment Ohridski, Bulgaria

- Belgian Nuclear Research Centre (SCK-CEN), Mol, Belgium

Associate partners in the world

- ITER International Organization (ITER IO)

- American University of Beirut (AUB), Beirut, Lebanon

- Peter the Great St. Petersburg State Polytechnic University, Russia

- National Research Nuclear University (MEPhl), Moscow, Russia

- Moscow Power Engineering Institute (MPEI,) Moscow, Russia

- Hefei Institute of Physical Sciences of the Chinese Academy of Sciences (ASIPP), Hefei, China

- University of Science and Technology Hefei (USTC) Hefei, China

- Southwestern Institute of Physics (SWIP), Chengdu, China

- Tsinghua University Beijing, China

- V. N. Karazin Kharkiv National University, Kharkiv, Ukraine

- Institute for Plasma Research (IPR), Gandhinagar, India

The rationale behind the choice of the full partner universities was as follows:

Nuclear fusion is basically a multidisciplinary field: plasma physics and related topics (turbulence, plasma-wave interaction, magneto-hydrodynamics, cryogenics and superconducting materials, numerical modelling, radiofrequency physics and technology, materials sciences, atomic physics and spectroscopy, etc. ). This was one of the reasons to build the consortium with eight full partners and many associate partners. It started with personal relationships between $\mathrm{HEls}$ with various skills, then the experience of a few years was used by the participants to develop the consortium towards a more complete and coherent curriculum (from theory to experiment, from physics to engineering, etc.). The fields of expertise of the involved partners/staff are complementary and of added value for the implementation of the programme through horizontal cooperation. Every full partner had already a fusion master track, as well as an associate research institution in close geographical vicinity, thus allowing easy exchanges of staff and close monitoring of the scientific collaborations. These close relationships guarantee that the FUSION-EP programme/stays aligned with the most recent developments in research and technology. Several scholars and lecturers of the full and associate partners give lectures in other sites so as to optimise the content of the course. The students thus benefit from the full range of expertise fields of the consortium. This situation guarantees that the students are given a substantial insight of the whole domain and a real possibility to choose between the fusion sciences track and the technology track, equally supported in the programme.

All partners and their backing institutions are in countries benefitting from the EUROfusion funding programme, an integrated scheme allowing the EU to coordinate the member-states' efforts on fusion sciences and technology through projects of various sizes and durations. These projects necessarily associate laboratories from various countries, including non-EU ones. All the EU (full and associate) partners have thus a long experience in international collaborations and multicultural environment.

The FUSION-EP programme, in addition to HEls, has secured the direct participation of two research institutes (IPP Prague, Czech Republic and CEA-IRFM, France) which open their laboratories and teams to the FUSION EP students in their second year. Two stays at IPP Prague and at CEACadarache during the second year of the programme are further opportunities to discover different countries or regions, with in Cadarache daily interactions with the local staff and with the students enrolled in the French national master programme (see section 4). The students thus experience not only teaching methods but also professional environments in up to 4 different countries.

The consortium is also in a particularly good position with regard to ITER, which is the focus of the attention for all students and researchers desiring to take part in the advent of the new, sustainable way of producing electricity from magnetically confined plasmas. Although ITER IO (due to its 
international statute) is bound to keep balanced relationships with all its members, the fact that the ITER project is located in the EU de facto facilitates the exchange of information and the establishment of specific collaborations. The coordinating institution of FUSION-EP, AMU, and its affiliated partner, CEAIRFM, have thus developed strong and frequent interactions with ITER staff members on scientific and technical activities, and some of them have co-supervised Master and PhD theses in the past few years.

Another reason to build this consortium was to promote excellence, originality, mobility, diversity as well as synergies of European universities and research institutions. Project leaders and engineers from leading industrial actors in the field of fusion give classes and seminars throughout the programme This international Master programme offers mandatory mobility and a multiple/joint diploma scheme offering a broad choice of specializations. The ambition is to become the reference of the Masters in magnetic fusion in the world.

The FUSION-EP programme provides a research-oriented education - in close connection with the activities of the academic, scientific and industrial partners - and an integrated language and cultural experience with aims to:

- $\quad$ attract highly-motivated students from top universities around the world

- groom global professionals with a long-lasting positive attitude towards Europe.

- deliver a high-level education in engineering physics complemented by practical experience and transversal skills e.g. organization, communication, language or e-skills.

- $\quad$ supply fusion R\&D with broadly educated physics engineers; especially ITER and the European national programmes and industries.

- continuously adapt the curriculum over the timescale of the ITER project and beyond, considering the technical evolution and scientific re-orientations in the field.

- develop an international network of academic and professional contacts.

The programme offers an opportunity for master level studies in a field which addresses the ever more urgent problem of world energy supply in line with the quantitative and qualitative requirements of the $X X I^{\text {st }}$ century. Its curriculum, described in section 2, focuses on technical applications of physics to the development of a clean, abundant, safe source of electric power by magnetic fusion. The 120 ECTS $^{1}$ coursework is supported by trainings at several laboratories partaking in the consortium. Two of these activities are commented below and described in more details elsewhere [4,5]. The combined and harmonized teaching and research activities equip the alumni with the wide variety of competences needed to take on leadership positions in university, research laboratories or industry. Meanwhile, progress in the field is generating important spin-offs [6], e.g. in the following fields: (i) from the exploitation of infrared thermography diagnostics in fusion tokamaks to the supervision of high temperature industrial processes; (ii) drones and infrared cameras to perform a thermal scan on a complex industrial environment; (iii) self-passivating smart alloys; (iV) ion beam analysis for Hubble space telescope; and (V) 3-D mesoscale soft X-ray microtomography for low contrast biological or soft samples. This progress calls for additional work force in two main categories: fusion science and fusion technology; see e.g. [7]. In section 3, the learning outcomes and attractiveness are discussed in the light of recent surveys on the alumni's professional development after graduation. The results show that FUSION-EP can supply the fusion community's need for broadly-educated physics engineers, complementing the existing higher education programmes in the countries of the partner institutions. Several synergies with the national fusion education programmes are presented in section 4 to clarify the role of FUSION-EP within European and global education networks.

It normally takes about ten years to acquire advanced knowledge and the skills needed to have full command of the discipline. Notwithstanding, after 15 years, the 200 alumni of FUSION-EP already play an important role in the community. These graduates know each other and have a strong sense of belonging to a group that has been provided a unique opportunity. Many of them, in return, make it a point of honour to provide similar opportunities and mentor the younger students. Further examples are presented in section 5, where we introduce FUSION-EP's global alumni community. We conclude this paper by offering some thoughts on the long term sustainability within the "thermonuclear" higher education area around ITER and Aix-Marseille University (AMU), which took over the coordination of FUSION-EP from Ghent University (UGent) in September 2019.

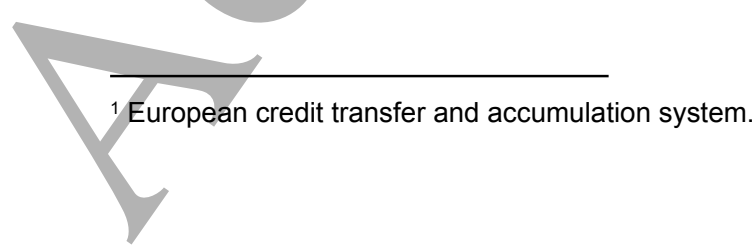




\section{The FUSION-EP curriculum}

A key point for EU leadership in magnetic fusion built since the 1960s is the availability of an increased number of skilled professionals, both in research and industry. The FUSION-EP curriculum has been defined to ensure that these professionals have a broad view of the challenges of fusion, beyond their specific expertise. Starting this effort at the master level and with a pan-European approach is of the highest relevance. Furthermore, the variety of topics taught in the FUSION-EP programme and its multidisciplinary approach, in addition to being necessary for the effective training of future fusion scientists and engineers, guarantees the employability of those graduates who wish to start a career in another field. The introduction of a cultural context is also an important innovation, largely due to the variety of origins and profiles of the students and visiting scholars.

Internationalization, multidisciplinarity and student mobility are inherent parts of FUSION-EP's structure and philosophy. The two-year track requires mandatory stays in at least 2 countries, typically a first year (M1) at university A followed by a second year (M2) at university B. Joint training sessions are organized in semesters 3 and 4, further expanding the students' mobility range and mingling opportunities. A summer event is organized every year, where M2 students defend their master thesis in front of an international jury and their fellow students. A sample study track is shown in figure 1.

Prospective students must hold a bachelor's degree (minimum 3 years full time study or 180 ECTS credits) in engineering or applied physics, physics or equivalent. Applicants are admitted on the basis of merit and a sufficient knowledge in classical and modern physics, including the necessary mathematical and computer programming skills. The first two semesters are spent in a single country (no student can spend them in his/her own country). For those with a great cultural difference as is often the case with Chinese or Middle-East students, this duration allows them to adapt themselves and settle before they have to move to a second country for the third semester. Moving to a second country and settling there is usually easier once the first European step has been taken.

The details of the curriculum are given in https://www.em-master-fusion.org/courses.

Recognizing the diverse academic backgrounds of first year students, M1 institutions provide a common basis in atomic and molecular physics, fluid mechanics, advanced electrodynamics, numerical modelling and plasma physics. These institutions include Aix-Marseille University, the University of Lorraine, Ghent University, Stuttgart University, Carlos III University of Madrid, and Complutense University of Madrid (the latter 2 universities offer the curriculum together). The second semester offers more flexibility thanks to a substantial number of elective courses (12 ECTS; i.e. 2/5 of a total of 30 ECTS) and lab projects (6 ECTS) reflecting the expertise of each site.

The second year focuses on the student's physics or engineering interests, taking advantage of the specific fusion engineering expertise of 3 more partners: the national institute of nuclear science and techniques (INSTN-CEA) in France; the Czech Technical University and the Karlsruhe Institute of Technology (KIT, via the University of Stuttgart). Again the specificities of each site are valued in the relatively high fraction of ECTS dedicated to elective courses (12 ECTS). 


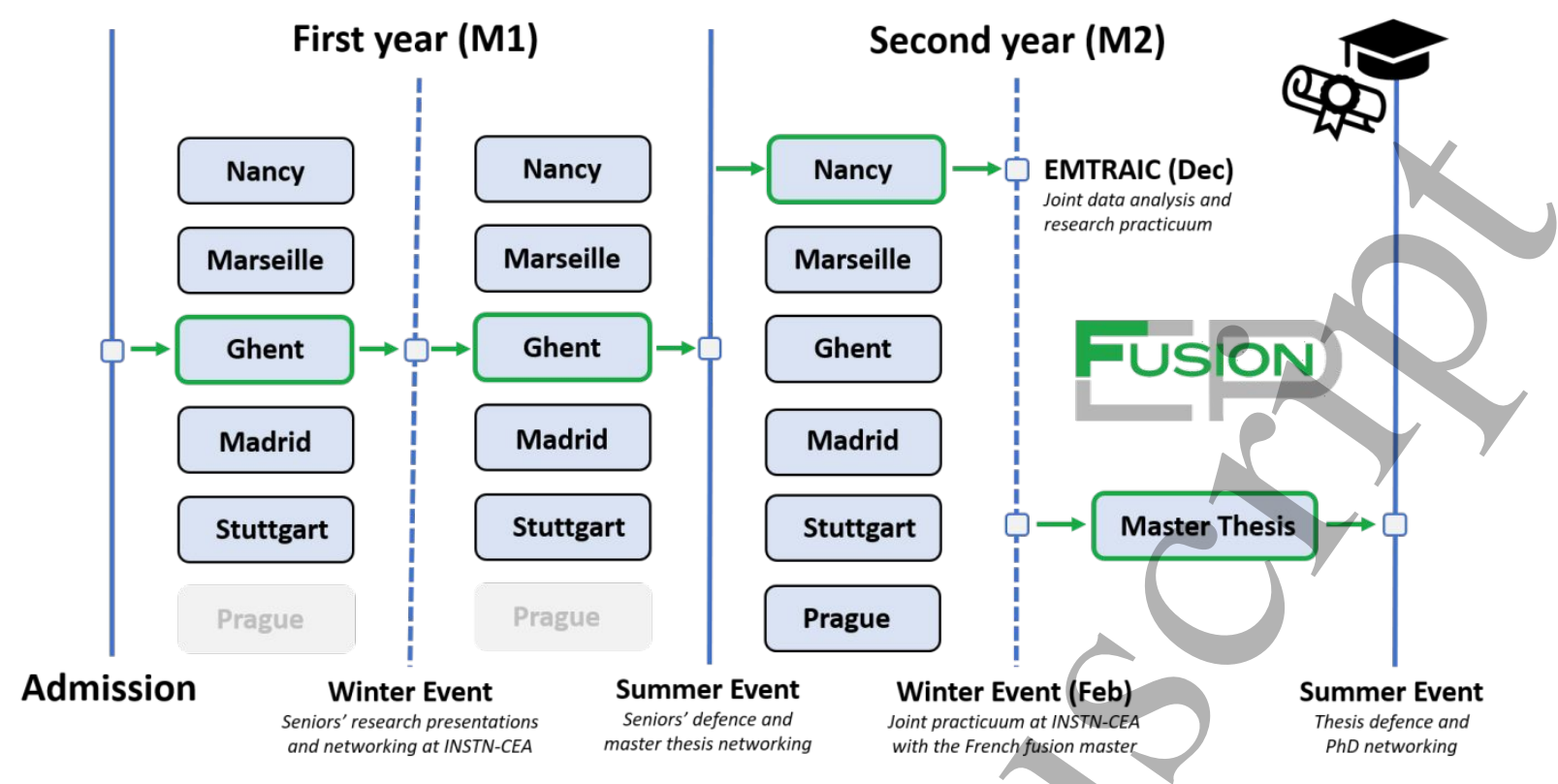

Fig.1. Example of a student's track in the FUSION-EP programme. A student is typically enrolled in the same university throughout the first year. At present, the Czech Technical University in Prague is a third semester choice only. The master's thesis work is carried out at the third semester university or an associate partner institution.

Joint training sessions provide M2 students with a common experience and exposure to world-class research personnel and facilities. These two mobility stays are valued 12 ECTS in total. The first session is a research-oriented experimentation and analysis session (EMTRAIC) on a research device (till 2020 the COMPASS tokamak) at the Institute of Plasma Physics of the Czech Academy of Sciences in Prague. During EMTRAIC, the students work in hands with senior physicists to plan and execute their experiment, process and understand the data and report their findings in a 20 minutes presentation followed by a formal report [5]. The student's work often contributes to larger scientific proposals resulting in a co-authored publication (e.g. $[8,9,10]$ ) or master's thesis collaboration. This additional incentive makes the "Prague event" one of the highlights of the programme. The second joint session ("Cadarache event") is all-the-more practical, consisting of two mini projects at INSTN-CEA and the (IRFM). On this occasion, the FUSION-EP students are paired with students of the French fusion masters under the supervision of CEA staff, lecturers and invited scholars. The projects range from the cooling design and testing of ITER plasma-facing components to the magnetic feedback control of fusion plasmas in the WEST tokamak. One such "mini hands-on" project is described with a wealth of details in [4]. The M2 cohort also visits the ITER site and attends seminars from ITER IO scientific and human resource staff providing yet another networking opportunity. M1 students participate at the end of this practicum when M2 students present their results in front of a jury. The M1 students are introduced to the practicalities of magnetic confinement fusion by a visit of the WEST tokamak hall and control room. They also meet the programme coordinating team and the local coordinators to discuss the master thesis possibilities before they choose their second year destination.

As a last requirement for graduation, students conduct their master thesis research at any of the partner institutions taking advantage of their particular expertise. Every year, at the end of July, the FUSION-EP students, alumni and coordinating teachers gather for the summer event. At this venue, the M2 students defend their thesis and are evaluated by an international committee. M1 students experience the standard to which their future thesis will be held and learn from the feedback on their seniors' written and oral delivery. The gathering provides ample time for students and alumni to exchange information on thesis projects, student life and career development perspectives at the study destinations and beyond. On commencement day, prominent researchers are invited to deliver hot topic seminars alongside high-level actors of the EU fusion programme and industrial partners, who provide orientation on employment perspectives in research or the industry.

The curriculum is kept up-to-date by the governing bodies of the consortium FUSION-EP. This procedure is open to representatives of industry so that they can share their needs and imprint them in the academic programme. This is done through the advisory board, whose role it is to suggest improvements and changes to the academic programme. Surveys among students also allow for the 
identification of strengths and needs for improvements in the curriculum design and in the teaching methods.

As the fusion community progresses towards commercialization, research is shifting from a fundamental science orientation to an industry-driven technological approach exploiting a growing number of synergies with the nuclear fission sector i.e. the "nuclearisation of fusion". In fusion education this is reflected as follows:

One of the raisons d'être of FUSION-EP is to contribute to the return on investment expected by the EU from the ITER project. The EU funds about $45 \%$ of the project. In return, the EU expects to receive the knowledge and know-how necessary for the EU fusion experts to build a commercial fusion reactor in Europe before the end of the century. This long term plan should be reflected in the objectives for the FUSION-EP programme for the near-term future. These objectives are to train the next generation of physicists and engineers who are needed.

There is a growing number of synergies with the nuclear fission sector. This is described and argued in the EUROfusion roadmap[2] which forms the basis of the European fusion programme and provides a clear and structured way forward to commercial electricity from fusion. Currently, one competence area is already being tackled within the European project ANNETTE (advanced networking for nuclear education, training and transfer of expertise), namely nuclear competences, with the aim to develop and implement the required training. The project is managed by FuseNet [see section 6].

In the second master year of FUSION-EP there is a complete track on fusion technology in the second year). Some core partners (AMU, Madrid) include courses on nuclear aspects. The participation of associate partner institutions like IRFM and INSTN in France, SCK-CEN in Belgium, CIEMAT in Spain, KIT in Germany, and CV REZ in Czech Republic facilitates the implementation of nuclear aspects in the curriculum.

Fusion research increasingly shows very important spin-offs in many fields of science and engineering, such as new materials, nanotechnologies, superconducting coils, robotics, electronic components, high power RF sources and space propulsion. This has been stressed several times by the Fusion Industry Innovation Forum (https://www2.euro-fusion.org/fíff/).

The graduates will have to be experts in their field, for most of them a narrow one. They should also feel comfortable through their interactions with professionals in very different subjects in a completely international environment. Although it has been an inherent feature of the magnetic fusion research domain for many years, the growing scale of the magnetic fusion plants and the transition toward a nuclear plant makes these international and multidisciplinary aspects more and more critical. Indeed, along with the growing size of the fusion devices comes the internationalisation. It has been particularly perceptible since the ITER project started. It is now visible at every level of the research structure. The young professionals must come out of this Master programme with a rooted conviction that internationalisation is a key to success. They must be well prepared to the issues brought about by an international environment.

FUSION-EP also aims at raising the worldwide visibility and outreach of the programme to a level comparable to the collaborations set up in the framework of the ITER project. The reason why Cadarache was chosen to host the ITER International Organisation (ITER IO, or simply IO) is that both magnetic fusion and nuclear expertise were already present on the CEA site. The coordination of the programme has been transferred from Ghent University to Aix-Marseille University with the aim of developing a large nuclear fusion Higher Education (HE) area superimposed with the nuclear fusion research area already existing between AMU, CEA-Cadarache and IO (see also section 6). The size of this HE area and the central place of the ITER project in the field of magnetic fusion will give the programme a high visibility and attractiveness. Many bilateral and multilateral links exist between the consortium partners and ITER IO. Moreover, the fact that the coordinating institution of the FUSION-EP consortium is geographically close to ITER, will contribute to make the programme more appealing. The geographical, topical and professional proximity of the coordinating partner with the central point that ITER has become, along with the participation of ITER IO as an associate partner, will allow an optimal alignment of the programme with the professional needs in the near future.

The programme ensures that the students develop a sense of initiative and are aware of the vast number of career opportunities in private companies. Their autonomy of choice and definition of career objectives is encouraged by the two proposed study tracks (physics and engineering), the wide panel of electives and the proposed Master thesis subjects. At AMU, the students must attend a compulsory project management course. The sense of autonomy, initiative and creativity is an essential part of the Joint experimentation and analysis session (IPP Prague) and of the Joint practicum (CEA-IRFM Cadarache). The students are placed in a position where they have to take the initiative and organise themselves to come up with a consistent strategy to address the problem put in front of them. Gathering 
and reading the literature, collecting available data, deciding on additional experiments and performing them within the available resources and time, analysing the results, deciding on the distribution of tasks between their group's members, writing the report, presenting the results, all these tasks must be done within the time constraints. This is a perfect preparation for the real life situation the students will encounter in their professional life. The next step is the Master thesis or internship, where each student is placed for several months in a real professional environment, either in a research institute or in a company. As each student has her/his own objectives to pursue, it is a valuable experience to develop autonomy, initiative, and organisation in the spirit of a project leader.

\section{Learning outcomes and attractiveness}

The FUSION-EP master is innovative in its course structure. The specific mobility scheme and the four semesters of study provide training opportunities for students who are looking for a programme evolving with the research context and the students' inputs about the learning process of fusion science and engineering. The programme also provides a genuine international opportunity, exposing the student to different cultural environments e.g. teaching methods and lecturer-student relationships.

The range of knowledge proposed during the first and second semesters is rather general. It is intended as a transition between the fundamental physics teaching of the previous years and the magnetised plasma physics applications taught in the third semester. The elective courses of the second semester and the (physics/ technology) track possibilities of the third semester are opportunities for each student to choose their future orientation. After these three semesters, the students are expected to be able to understand the basic principles of each topic so that they can interact with researchers and choose their Master thesis subject. They are also required to have the necessary background to start their thesis by building a specific bibliographic database, developing simple but appropriate models, grasping the assumptions and limitations of previous work and in a short time becoming actors of their own thesis project.

The learning outcomes are detailed below by a distribution in two categories (see table): topicspecific skills applicable in the field of magnetic fusion or related fields, and transferable skills which can be applied in any field, even outside research and development. The topic-specific skills, as mentioned above, include the capability of devising models as a way to represent mathematically an engineering or a physics situation by means of a set of equations. The wide range of teaching courses during the third semester will be used by the student to grasp the interdependence of her/his subject with other topics, look for the appropriate equations, couple models relevant to different topics in order to produce a new vision and a new model. The student will also learn the vocabulary and the types of reasoning used in topics outside her/his own so that she/he can cooperate with researchers outside of the team. The possibility of mitigating the dual track choice by including lectures from the other track is also intended to train the students in both aspects (physics and engineering) which are very often interdependent in magnetic fusion.

\section{Table - Learning outcomes}

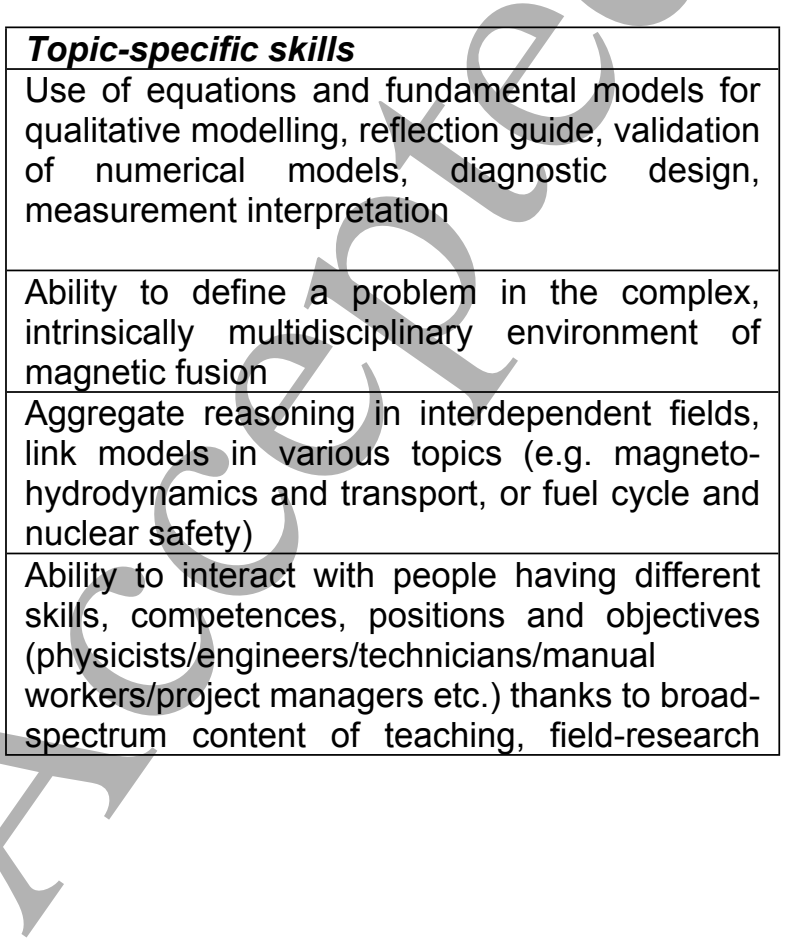

Transferable skills

Adaptation to a different cultural environment (semesters 1-3) thanks to placement in foreign universities, to multicultural environment (Prague \& Cadarache events, summer events) Bibliographical search of relevant information, building basic knowledge relevant to the studied topic Analytical and critical reading of written documents (internal or technical notes, published articles)

Oral and audiovisual transmission of information during meetings and oral talks to specialist and non-specialist audience 
periods in Prague and Cadarache and a 4-6 month placement during Master thesis

From academic models in form of equation systems, derive pragmatic work plan and details of technical or numerical design and operation

Develop and use both generic and fusionspecific numerical methods for:

- theoretical models of plasma dynamics

- empirical models of experiments and synthetic measurements
Knowledge and use of specificities of scientific literature for elaboration and publication of high quality articles

Team work, build research projects using related work by other teams and place one's work in a collective dynamics of research

Ability to

- understand architecture of complex codes and code versioning,

- perform numerical calculations,

- develop basic and advanced

algorithms

The transferable skills developed in the programme are essential in magnetic fusion because of the increasing internationalisation and the high degree of integration of various physics and engineering domains. The first step to internationalisation is the multicultural experience the students get during their first year in a university abroad, where they will not only have a language and culture course, but also practice the country's language and experience the country's culture in their everyday life. They will be in direct contact with local teaching methods and different types of lecturer-student relationship. During the first year, they will also work remotely with the whole group of FUSION-EP M1 students on the GOLEM tokamak of full partner university CTU in Prague. They will learn to work in a multicultural group and face related issues in a situation where they have to organise themselves in a large part (the supervisor playing the role of scientific mentor and, if needed, moderator). As this is the first opportunity for the M1 students to get together (remotely), this will serve as an integrating tool for each new intake. The multicultural experience of a professional environment is then acquired by the students during the M2 mobility stays at IPP Prague and CEA Cadarache, including a meeting with the multicultural actions responsible officer and members of the ITER staff. These two mobility stays are designed to develop a spirit of initiative and input from all students. They are encouraged to elaborate ideas on practical cases, either at the COMPASS tokamak or at the CEA-IRFM laboratories. It is often noticed that many students are somewhat inhibited in front of an experimental set-up, especially a large one. The supervisors help them stretch their imagination in the definition of their objectives and methods before guiding them through the practicalities and limitations of the experimental set-up, so that a balance is reached between ambitious goals and feasible experiments. Results from the the 2-weeks Joint experiment and analysis session at IPP Prague have sometimes been included in regular publications (see e.g. $[8,9,10]$ ), a proof that the students can produce a valuable research work at the end of three semesters at FUSION-EP.

Other transferable skills such as the ability to lead a bibliographical study in a given subject, to read and synthetise published articles, to use them in their own research, are acquired mostly during the Master thesis research. Nevertheless, several opportunities are given to the students to develop their ability to look for relevant documentation, to prepare and present oral or written reports to communicate their work to other students and researchers. In addition to what can be proposed by the lecturers during the academic course, the Prague and Cadarache events are especially suited to put the students in situations similar to what they will experience in their professional life.

Among the transferable skills, it appears from the alumni database that IT is one of the most useful regarding employability of the FUSION-EP graduates. The physics of magnetised plasmas, highly nonlinear, has long been and still is an attractive though challenging topic for numerics experts. Generic as well as specific methods are/developed and applied to magnetic fusion issues. Material sciences applied to components of fusion devices are also a good source of inspiration. Compulsory courses and electives complemented with practical work (see https://www.em-master-fusion.org/courses), the Joint experiment and analysis session (M2, Prague), the Joint Practicum (M2, Cadarache) and research periods on these matters are designed so that the students learn about these methods and the various IT environments in which they are used.

The consortium FUSION-EP established a set of internal and external evaluation methods to monitor, upgrade and improve the quality of the course.

Internal project evaluation is implemented as follows: for design and approval of programmes, the intended learning outcomes are defined by the consortium's steering committee (SC) which 
determines guidelines. The programme is designed by the executive committee according to these guidelines. This programme is then approved by the SC. This process is coordinated with the HEl's respective Master programmes. The consortium regularly checks if the students have acquired the learning outcomes. For the technical aspects, the exams on the courses guarantee an impartial and correct evaluation. For an evaluation of transferable skills or "soft skills", the joint training events at IPP Prague (Czech Republic) and at CEA-Cadarache (France) during the second year are best suited: there is an evaluation by supervisors (ability to work in a team, to define a scientific question in a complex environment, to use the academic achievements of other fields of knowledge) and an evaluation of the presentation and the report; all these tasks must be fulfilled within the time constraints.

For External quality assurance (QA) the programme is annually assessed by the FUSION-EP advisory board composed of representatives from industry, fusion research institutes and universities. The FUSION-EP programme undergoes screening by the respective national evaluation agency in accordance with the assessment regulations of the HEls involved in the programme. Several national quality assessments have been made, with very positive outcome. The accreditation of these Master programmes is granted by the relevant national agencies. The consortium also intends to formally request and to submit to a single evaluation of the entire joint programme, foreseen in the directive of the European approach to QA for joint programs, approved by the EHEA ministers in May 2015.

A recent survey of the alumni community is summarized in figure 2. This data was complemented with information found on FUSION-EP and public records, e.g. Linkedin, and shows that $68 \%$ of the alumni pursued doctoral studies while $20 \%$ went straight to work. Of those starting a PhD, $70 \%$ had already obtained their doctoral degree while for $30 \%$, it was still in progress; c.f. figure 2-a. A large majority chose a research topic in fusion science or fusion engineering. Most of the remainder, as can be appreciated in figure 2-b, specialized in the domain of plasma physics or plasma technology. Overall, 130 alumni reported to be on the labour market, 39 were still finishing their doctoral degree and 21 could not be reached. Among the former, 47 alumni had started a postdoc, 32 of which were already completed; 61 were employed in the private sector, 34 found jobs in national laboratories, and 14 stayed in academia. The pursuit of $\mathrm{PhD}$ is quite an important career step, which affects future employability in a positive way. Three out of the five unemployed alumni in figure 2-c are students who graduated within the year and chose not to pursue a PhD. A large fraction of the master students thus continues for a $\mathrm{PhD}$, having been attracted by the high level research they were exposed to. However, in the longer run, our statistics showed that almost 50\% end up in industry; see figure 2-d.

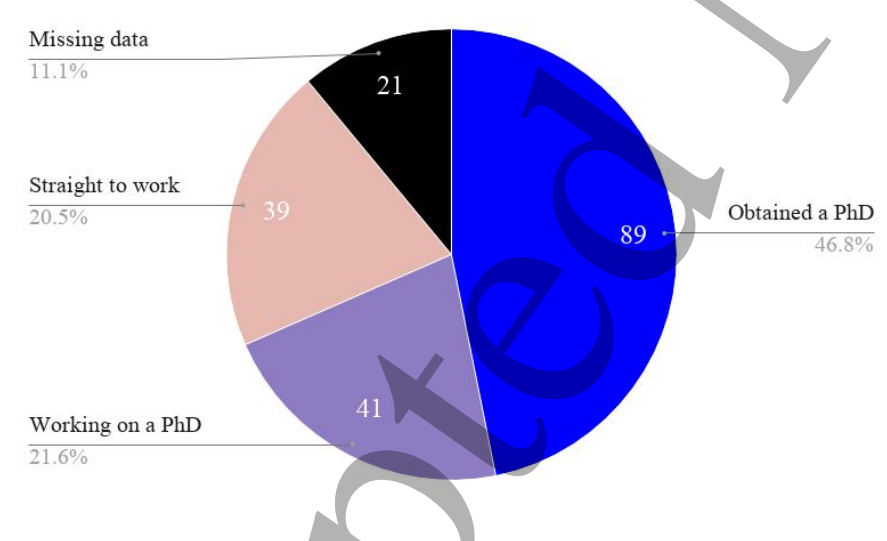

2-a. Nearly $70 \%$ of the FUSION-EP alumni pursues doctoral studies after graduation.

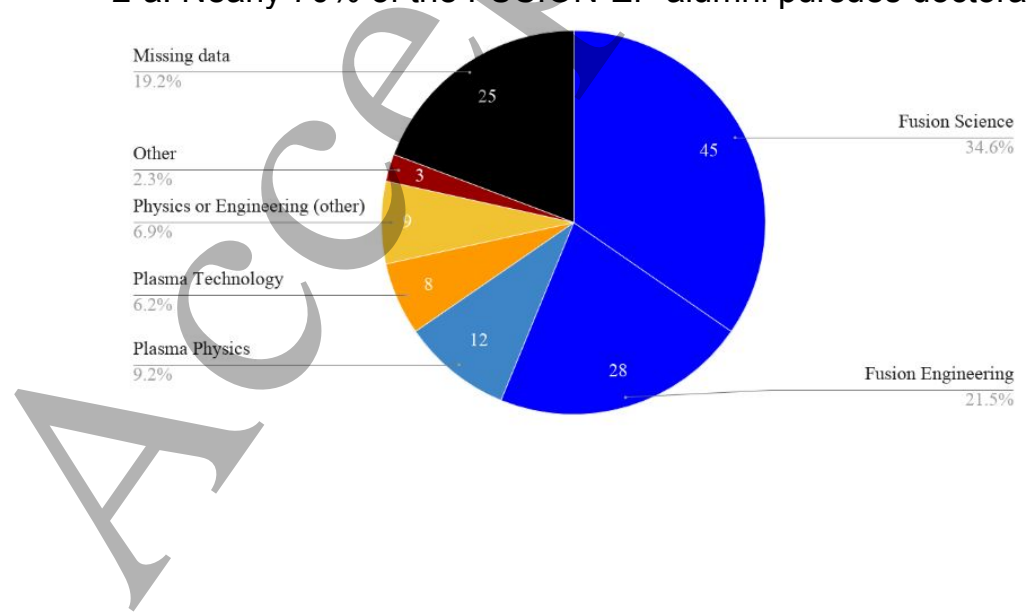


2-b. More than $50 \%$ of the FUSION-EP alumni who pursue doctoral studies do so in fusion science or engineering. Nearly $15 \%$ of the remainder studies plasma physics or technology.

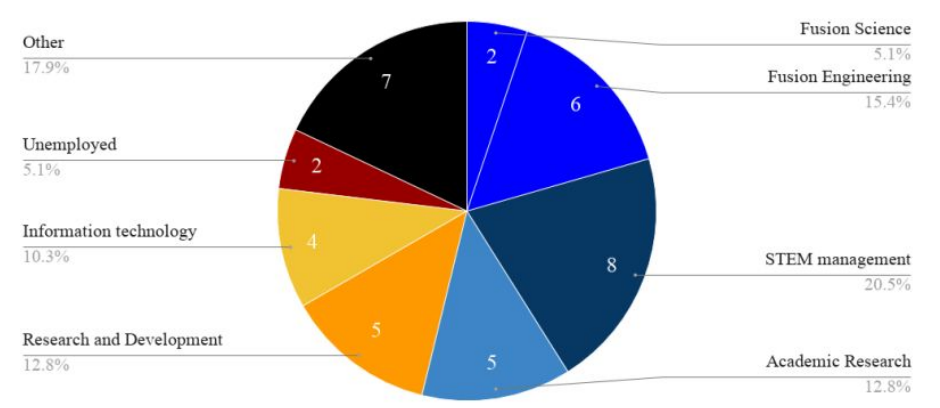

2-c. From the FUSION-EP alumni who decide to work directly after graduation: more than $30 \%$ continues in fusion or academic research (including but not limited to topics in fusion and plasma research); a very large fraction takes on leadership positions in STEM (science, technology, engineering and mathematics) management or industry research and development. The unemployment fraction largely corresponds to recent graduates who chose not to pursue a PhD.

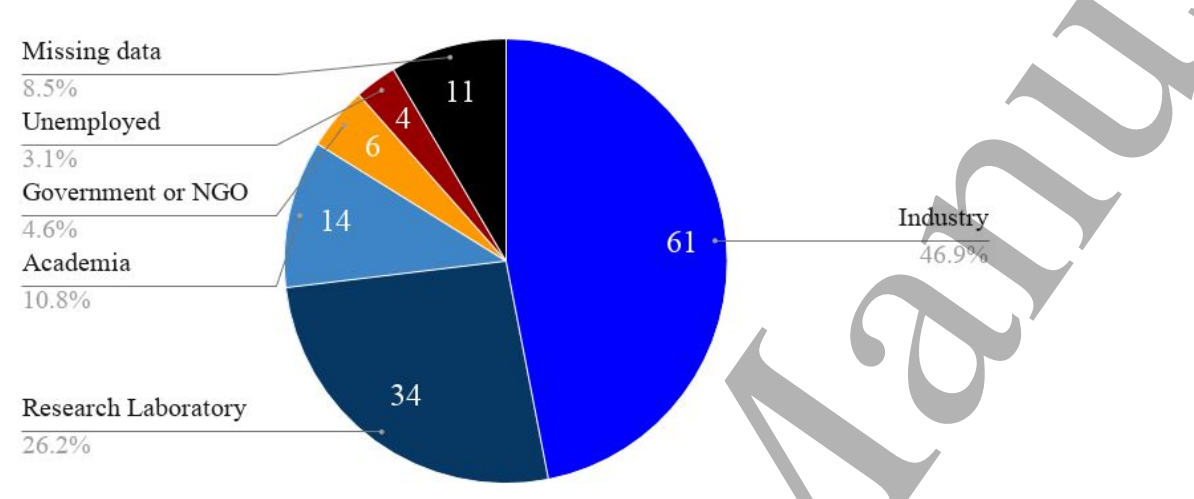

2-d. On the long run, nearly half of the FUSION-EP alumni are employed in industry. Close to $40 \%$ is absorbed by national laboratories and academia.

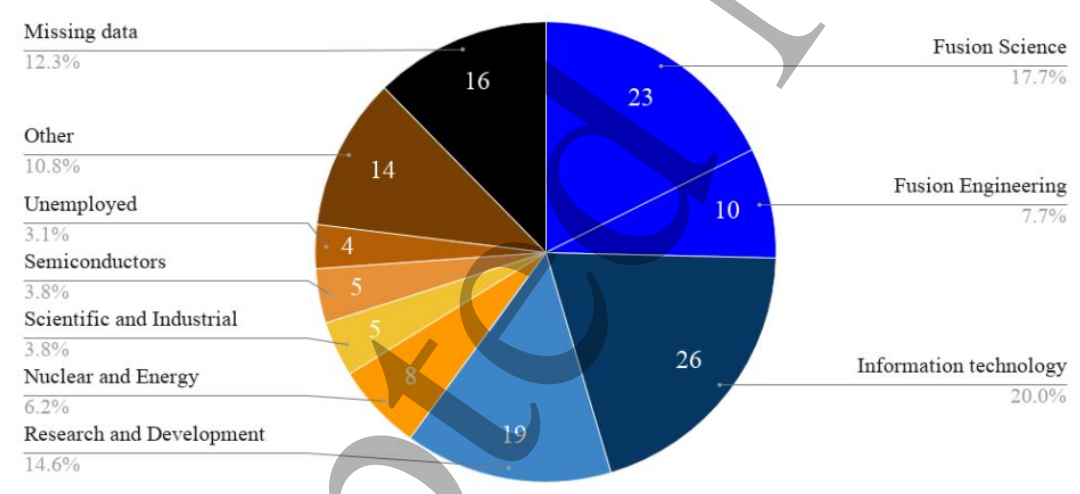

2-e. On the long run, $25 \%$ of the alumni work in the fusion while a third continues in the broader field of nuclear, engineering, research and development.

Fig. 2. Results of a 2020 survey describing the career path of FUSION-EP alumni post-graduation.

Out of the 130 alumni who reported to be working, $25 \%$ continues in fusion science or engineering while $20 \%$ continues in in the broader field of nuclear, engineering, research and development. One fifth reconverts into information technology: this includes software engineers and data scientists, as well as high-performance computing and telecommunications engineers. A large fraction of FUSION-EP students tends to continue in fusion, plasma or nuclear research and engineering. This is not surprising since those students usually choose this direction in a very focused way. Their exposure to physics and engineering, research and more applied R\&D allows them further to choose within these areas the direction that suits them best. This enables the programme to achieve the goal of providing the fusion 
research programmes (in particular the EU one and ITER) and industry with the needed workforce (see section 4).

Further results from a 2016 survey (with a response rate of $60 \%$ i.e. 100 out of 164 alumni) show that $85 \%$ of the respondents found that the obtained master diploma was very helpful to find a job; $77 \%$ stated that the joint aspect of the diploma is useful and the mobility to other universities was an added value; $92 \%$ of the alumni was satisfied with their current status. None was reporting to be looking for a job, confirming the high employability of the graduates of the programme.

The results of the surveys show that FUSION-EP can supply the fusion community's need for broadly-educated physics engineers, complementing the existing higher education programmes in the countries of the partner institutions (see section 4). It normally takes about ten years to acquire advanced knowledge and the skills needed to have full command of the discipline. After 15 years, the 200 alumni of FUSION-EP already play an important role in the community, and we have very positive feedback from a multitude of research institutions and private companies.

\section{Global academic outreach}

The total number of staff in the EUROfusion programme is about 3000 scientists and engineers. According to a Human Resource survey carried out in 2015/16, a healthy system should aim at some 300 PhD students (i.e. 100 new PhD students per year) and an equivalent number of engineers active in the fusion community, with an appropriate spread over topics in fusion engineering and physics. Although it has been an inherent feature of the magnetic fusion research domain for many years, the growing scale of the magnetic fusion plants and the transition toward a nuclear plant makes these international and multidisciplinary aspects more and more critical. This has been stressed several times by the Fusion Industry Innovation Forum (https://www2.euro-fusion.org/fiif/).

In response to the start of the international ITER project in Cadarache (France) in 2005 various master education programmes have been set up. Most of them are national programmes. FUSION-EP is the only truly international master programme in the fusion area. Other programmes make international selection ( like in France: see below; Italy: University of Rome "Tor Vergata" ; UK: University of York, etc.) but the FUSION-EP programme is the only one which is built upon a consortium of international HEls which work together on the programme design, provide a variety of pedagogical approaches, visions of the field, and working methods. FUSION-EP offers the students a well-structured and mandatory international mobility scheme between the first and the second years and 4 short stays along the two-years programme, and uses the complementarity of the international partners to provide the students with a broad choice to cover their needs. Another important objective of FUSION-EP is to introduce the students in the industrial world, and to offer possibilities of placement periods for Master thesis to all students either in private companies or in research laboratories. This aspect is more difficult to assess in the national master programmes, although most them propose the students to lead their master thesis in private companies as well as in research laboratories.

There exist 13 Master programmes (one or two years) in the EU such as the fusion-dedicated Master at the FUSION-EP Associated Partner Sofia University, and the fusion tracks within physics or engineering Masters such as at Budapest University of Technology BME, University of Lisbon-IST, Ecole Polytechnique Lausanne EPFL-SPC in Switzerland, Karlsruhe Institute of Technology KIT, etc. In particular among the members of ITER IO (China, European Union, India, Republic of Korea, Russian Federation and USA), there is a direct interest in the training of competent scientists and engineers in this field. In China, the USA (and Canada), Korea and Japan, it appears that there is no internationally structured programme specifically dedicated to fusion. This makes FUSION-EP a very attractive programme for the students of these countries seeking an intense two-years comprehensive training on magnetic fusion. Indeed the FUSION-EP programme is structured to give the students a complete vision of the field with skills directly usable in a professional environment in just two years.

In Europe, the programme closest to FUSION-EP is the French national master on fusion and plasma sciences FedSPF proposed by a federation of French HE institutions since 2004. This programme collaborates closely with FUSION-EP. Depending on the site they choose, the students can follow various pathways among which fusion attracts every year about 25-30 students, either in a physics oriented course or in an engineering course (other pathways are cold plasmas, laser plasmas and inertial fusion, etc.). The $25 \%$ of non-French students come from countries in Europe (including non-EU Eastern countries), Russia and South Mediterranean countries (Maghreb, Lebanon). Nevertheless there is neither an international recruitment policy nor particular means developed to attract the best students worldwide. In addition to the academic partners, it has a strong link with CEAIRFM which is in charge of organising for the M2 students a 4-weeks' mobility aimed at immersing the 
students in a large fusion research laboratory where they have hands-on technical projects and a 2weeks project (together with FUSION-EP students) in small groups to conceptually design a tokamak. The fusion master programme of Eindhoven University of Technology (Netherlands) also fulfills a large number of the EMJMD objectives but, like the French programme, it is not structured as an international consortium with a mobility policy and an international student recruitment policy. It is technology oriented and thus the link between fundamental research and technology development is not as strong as in FUSION-EP.

FUSION-EP is thus the only programme in Europe which, by means of a selective international recruitment, long- and short-stay mobility periods, sociocultural immersion and multicultural work activities, tackles the issue of fast and thorough internationalization under the impulse of the international ITER project. The European master does not substitute but complements the national fusion masters. Indeed, the French master at AMU recognizes explicitly the importance of FUSION-EP and cultivates strong bonds of cooperation. Similarly, one of the driving forces in the Dutch fusion master is a lecturer for the FUSION-EP programme at Ghent University.

There is an objective competition between the fusion masters in the sense that students interested in fusion can apply to more than one master programme. However, benefitting from a European funding for the next 5 years the consortium FUSION-EP has a responsibility in seeking to develop synergies and cooperation between the European programmes. It can take various forms such as widening the audience of remotely organised seminars or evolving the annual summer events into more open events. It is thought that, thanks to the interactions between FUSION-EP and national programmes e.g. through EMTRAIC and the winter event in Cadarache, and the FusionEPtalks organised by the alumni (see section 5), the FUSION-EP programme can have an 'internationalising' effect on national programmes.

The EMJMDs like FUSION-EP promote promote the visibility and attractiveness of European higher education in non-member countries [3]. Top-ranked Russian Universities such as the National Research Nuclear University (MEPhl), the National Research University "Moscow Power Engineering Institute" (MPEI) or the Peter the Great St. Petersburg Polytechnic University are associate partners of FUSIONEP. These universities have adopted the European bachelor-master system and provided close to $15 \%$ of the FUSION-EP alumni; c.f. figure 3. An agreement is being finalized between FUSION-EP universities and MEPhI to facilitate the exchange of students by recognizing the credits gained in both programmes and defining a double-degree in the field of physics and technology of controlled thermonuclear fusion. It will also create opportunities for the lecturers of one programme to visit the other, to the benefit of the students. This agreement is fully consistent with the FUSION-EP's principle of exposing the students to an international environment and leveraging competences in an international partnership. The AMU/MEPhl agreement is a starting point for similar agreements with all associate partners (section 1), in particular those in the ITER member countries. ${ }^{2}$

While FUSION-EP does not aim to make a substantial addition to the number of graduates in nonEuropean ITER member countries, it will offer their best and brightest a world-class education in fusion engineering physics. Two-years of experience among international research teams that have been invested in ITER for several decades will make them ideal candidates to work on ITER and national fusion efforts for their own countries. This is especially true as the students establish their professional networks within the EU that is paying for almost half of the ITER project. The ITER organization itself is well aware of the present and future demand in terms of workforce and the importance of FUSION-EP in fulfilling these needs. The pronounced interest of ITER IO is concretely expressed in their willingness to provide master thesis internship topics and supervision for M2 students. The unique technological expertise at ITER IO is an important asset for FUSION-EP, while ITER benefits by getting to know the students first-hand. Fifteen years of experience demonstrate the added value of a flexible graduate studies programme emphasizing mobility and the pooling of scientific and technological competences for education.

In view of a stronger bond with industry, the consortium works in different directions to arouse the FUSION-EP students' interest toward private companies and to prepare them to industrial careers and entrepreneurship. Furthermore, as outlined above employers are involved in course implementation in order to improve students competencies and skills and thereby enhance the employability of graduates, and entrepreneurship and a sense of initiative are encouraged.With 8 full partners , 25 associate partners, and private companies there is ample provision of Master thesis and internship subjects every year. During this time the students get their first professional experience, and enrich their

2 "As signatories to the ITER Agreement, the ITER Members China, the European Union, India, Japan, Korea, Russia and the United States will share in the cost of project construction, operation and decommissioning, and also share in the experimental results and any intellectual property generated by the project" [1]. 
network. They are included in a research laboratory or in a private company, participate in and contribute to their team's work. Fusion for Energy (F4E), the European Union's Joint Undertaking for ITER and the Development of Fusion Energy, has initiated an action with companies registered with them to provide FUSION-EP a list of all the companies interested in our activity with their contact details. F4E will interface between European industry and FUSION-EP for internships and placements. The industrial members of the advisory board and the steering committee are further contact persons for those more interested in theses in industry. The industry is represented in the consortium's SC as well as in the management board of the fusion industry innovation forum (FIIF). Furthermore, in 2019 a FUSION-EP alumnus working in industry has been selected as a member of the management board of FIIF.

All EU countries have a national ITER coordination unit to effectively inform local companies about the ITER project and involve them in its realization. These units are closely assisted by the EUROfusion Consortium. Together with the involvement of the ITER International Organization these promote the involvement of industry in FUSION-EP. ITER IO is committed to become a link between FUSION-EP and private companies contracting with ITER. In order for this to be effective on the long term, the coordinator will work with the communications staff member designated by ITER IO as the FUSION-EP contact person. A participation of FUSION-EP to the biennial ITER business forum (http://www.iterbusinessforum.com ) allows to meet companies at regular intervals so that the FUSIONEP network with the private sector is updated.

With AMU, full partner of the consortium since 2015, the programme has access to the companies that have in the past provided internships to their students, as well as to industrial companies where former students were hired. These include Altran, AREVA (now Orano and Framatome), EDF, LGI Consulting, PHIMECA Engineering SPIE Nucléaire, SOLVAY, Thyssen Krupp, Polysius. FUSIONEP is supported by F4E, that strives to broaden the European industrial base for fusion technology for the long-term development of fusion as a future energy source and to ensure a strong and competitive European industrial participation in the future fusion market. F4E is committed to promote FUSION-EP among its industrial partners. Their geographic location puts AMU, CEA and ITER IO in the position of an already effective cluster both for research and for education and traíning whose visibility even outside Europe can be readily advertised. In addition, numerous industrial companies having contracts with ITER IO are present in the geographical area and also host Master theses or placement for students in engineering.

In Spain the capabilities of Spanish companies for fusion projects are summarized in the document 'Spanish industry capacities and activities in fusion energy', released by the Centre for the Development of Industrial Technology (CDTI) and the Spanish Ministry for Economy. It discusses the recent success of entrepreneurial endeavours related to fusion and includes a complete picture of the skills and competitiveness of Spanish industries in the field. A strong link to the need of trained researchers and engineers is underlined in the context of ITER, at the national and international levels. This is definitely a path to explore for internships and graduate's employment.

The alumni database is also an extremely valuable source of contacts. Indeed, the alumni who started their own company or are employed in private companies (17\% of all alumni) are already aware of the programme's quality and the interest of young professional trained in a multicultural environment, as shown for example by APREX Solutions (see section 5). They are also aware of the high quality work and high level of involvement that can be expected from Master students during an internship or a Master thesis.

\section{Students and alumni self-organization}

There are nearly 200 students and alumni in the global FUSION-EP community outlined in figure 3. Right from the start, a Facebook group was formed to keep an open channel between students and alumni of the European Fusion Master and Doctoral programmes. This forum is moderated by the alumni to help new students navigate and leverage the network. Most of the discussion focuses on concerns of administration, finance or cultural and professional acclimatization. Training and networking events, community news, memories and (post)doctoral openings are also shared among the alumni. 

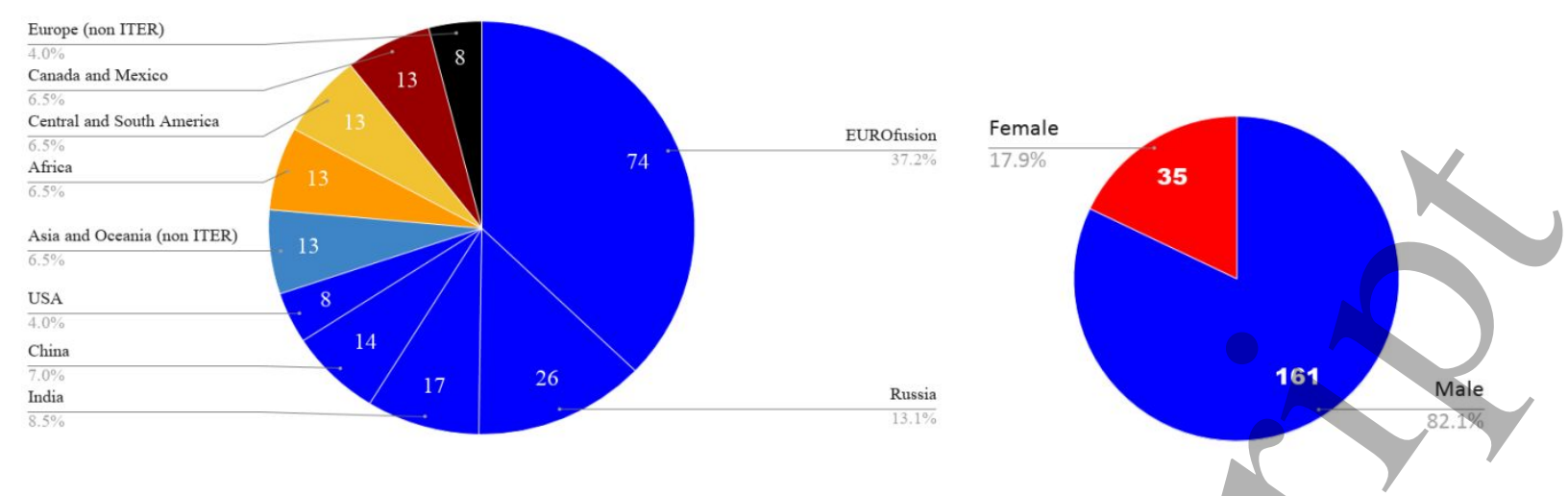

Fig. 3. Geographical and gender distribution of the FUSION-EP students and alumni. ITER member countries are shown in blue and comprise over $70 \%$ of the student body. For non-partner countries, the geographical distribution is equal. Note that there is only one alumnus from Oceania (New Zealand).

Gender balance is a generic problem for all STEM fields, and it gets more serious with increasing level of diploma, so master degrees all face the same problem in its most serious form. EUROfusion has shown that the gender balance is better in the southern than in the northern European countries. The selection procedure of FUSION-EP seems an appropriate step to improve the balance, and this is where it is done indeed and positive discrimination is applied in case of equal qualification: priority is given to female students. However, this cannot be at the expense of excellence, and therefore other actions are required, such as the promotion of fusion sciences at secondary school level are. As an example, FuseNet Association (see section 6) is organizing European fusion teacher days, open to all science and physics teachers in Europe. One of the main elements of the FuseNet Association is coherence by ensuring better links between the different education layers to optimise the flow of students through the system. Therefore, there is a focus on secondary school teachers and connections with higher education and fusion research institutes. IAEA offers scholarships for female students, to promote the place of women in nuclear sciences through masters scholarships, and future FUSION-EP students will apply (https://www.iaea.org/about/overview/gender-at-the-iaea).

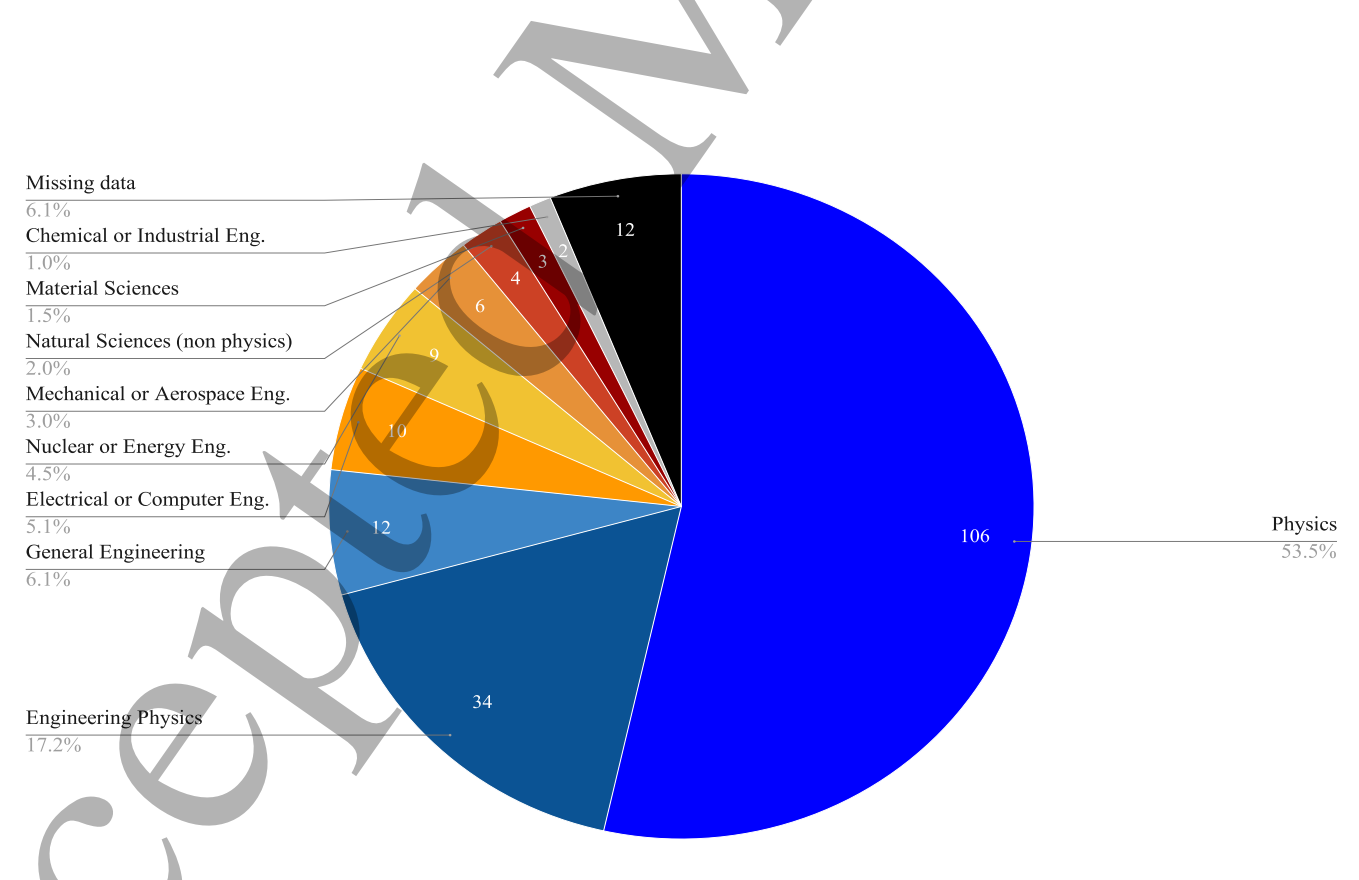

Fig 3. Field of study distribution of the FUSION-EP students and alumni. It is worth mentioning that $6 \%$ of the alumni joined the programme as a second master.

At the crossroad of research areas, newcomers often struggle to make informed career choices. The alumni community can provide orientation by sharing practical advice, organizing guided visits to fusion laboratories and facilitating introductions to prospective employers or research promoters. 


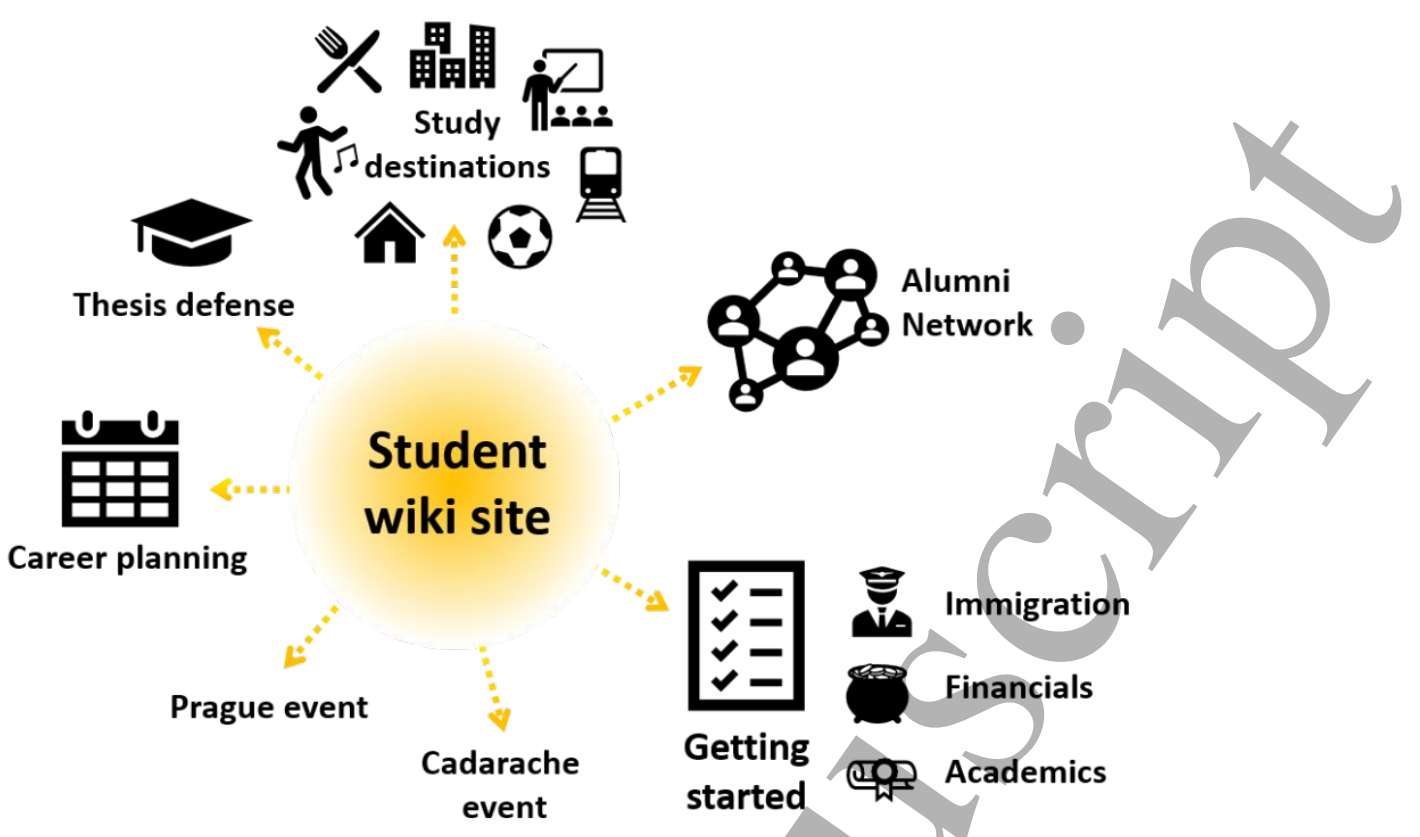

Fig. 4. Graphical representation of the "Fusioneers' Wiki", an informal site maintained by the alumni for future generations of FUSION-EP students.

Recurring questions among students are bundled on the "Fusioneers' Wiki"[11], depicted in figure 4 , which provides an insider view of the programme structure, activities and destinations. In essence the wiki covers all of which the alumni wish they knew before setting off on their adventure!

Student self-organization materializes in several ways, but the loose structure of the network keeps large fractions of the alumni in the dark until solicited as mentors or commencement speakers. While social media have been instrumental in consolidating the alumni community, the present infrastructure fails to include those who do not maintain social media accounts. This is the case for alumni at a later stage of their career or those based in countries where the internet is censored. The Facebook experience shows that opportune communication and the creation of incentives, like sharing news or job openings, can maintain the alumni active within the community. However, an active engagement requires sustained efforts by an appointed (student or administrative) manager online or at the occasion of an alumni event. Looking to the future, it may be important to consider different means to cultivate these connections such as an email list, and alumni portal or events involving the alumni.

Meanwhile, several student and alumni initiatives have nurtured and leveraged meaningful connections within the network. For example, in France, the fusion spin-off APREX Solutions [12], specialised in machine vision and image \& video analysis, is run by two French alumni and two scientists affiliated to the University of Lorraine. In Egypt, several Summer Schools and Courses have been pushed forward by FUSION-EP alumni under the umbrella of the Egyptian Plasma Society (EGYPlasma) - which regroups hundreds of plasma scientists and engineers with aims to host local and international events in plasma physics while enabling a healthy research environment for young generation to learn about plasma and its applications.

Another such undertaking was a non-profit, non-governmental organization (NGO) in the Balkans named $\mathrm{FOM}^{3}$. The NGO was founded and run by five FUSION-EP alumni from Serbia, Montenegro and Bosnia and Herzegovina. The FOM team was active from 2015 until 2018. During that time FOM organized and coordinated three summer schools/workshops called "fusion days", which took place at the University of Belgrade or the University of Novi Sad in Serbia, and included a remote experimental training course on the GOLEM tokamak [13] of the FUSION-EP core partner university CTU in Prague. Beyond the fusion days, the FOM team supported 40 participants through the FOM/junior programme by arranging internships and projects at several European institutions via the FUSION-EP network. Overall, FOM encouraged more than 70 undergraduate students to pursue fusion research, many of which joined FUSION-EP. 
One last example is the FusionEPtalks platform, which proposes student-led fusion webinars [14]. In just about two years, more than 30 such meetings have been hosted on the video-conference application ZOOM. The informal nature of the discussion allows junior scientists to delve into lively discussions with members of our community, friends, collaborators and enthusiasts from all over the world. The variety of topics in the field of controlled fusion and the diverse nature of the audience connects prospective students to the alumni and to members of the international fusion community and enthusiasts.

Much like EGYPlasma and FOM, FusionEPtalks speaks to the cohesion of the FUSION-EP alumni community and the driving force of student self-organization.

\section{Outlook, future orientation and sustainability}

The FUSION-EP joint master's degree addresses a growing need for broadly educated physics engineers qualified in the nuclear fusion energy sector. The programme offers a select group of top graduate students the means to accomplish their education and training within an international consortium of institutions leading the interdisciplinary field of magnetic fusion. The mobility structure of the programme, the open nature of the curriculum, and the emphasis placed on knowledge transfer from one cohort to the next result in an experience that is much greater than the sum of its parts. For instance, the Prague joint training session EMTRAIC provides a unique and unforgettable opportunity to work at the heart of fusion research for those who later choose to pursue an engineering career. Similarly, the joint training session in Cadarache is a chance to sample a wide spectrum of activities and technologies constituting a nuclear fusion reactor. This framework clearly provides an added value with respect to the national fusion education programmes in terms of:

- leveraging the full potential of European master-level education in fusion by widening the students' perspective and personalising their career development;

- $\quad$ access to a range of world class fusion facilities and researchers;

- $\quad$ promoting common education and scientific standards, worldwide interpersonal contacts, and a corporate spirit for collaborations between EU and non-EU scientists and engineers, as will be essential for the ITER project;

- $\quad$ extending international partnerships between higher education, fusion R\&D and industry;

- $\quad$ supplying broadly-qualified physics engineers to ITER, DEMO and national fusion programmes;

- $\quad$ supplying the industry with mobile leaders who have experience with, and a positive attitude towards, top-level R\&D and a multicultural environment;

- $\quad$ enhancing the international profile and visibility of European higher education worldwide.

FUSION-EP is thus the only programme in Europe which, by means of a selective international recruitment, long- and short-stay mobility periods, sociocultural immersion and multicultural work activities, tackles the issue of fast and thorough internationalization driven by the international project ITER. No single university can offer such a variety of competences and expertise as the one available across the full partners. It is a unique opportunity for each student to build his/her own curriculum according to his/her background, objectives and cultural affinities and curiosity. The objective is to enhance further the international character of this higher education programme by drawing advantage from the structuring role of the ITER project in fusion sciences. ITER is at the center of a world-wide research network in which the consortium partners are active contributors. Following the example of ITER, the FUSION-EP programme seeks to reinforce its position as a leader in education by integrating the fusion HE in the same way as ITER integrates the nuclear fusion research efforts of its members (China, EU, India, Japan, the Republic of Korea, the Russian Federation, and the USA).

The most accomplished example of the attractiveness of the FUSION-EP programme is the cooperation agreement with its Russian associate partners MEPhl, MPEI and Peter the Great St. Petersburg Polytechnic University. They advertise the programme among their students and many of the Russian students who graduated from FUSION-EP came originally from there. An agreement establishng a double-degree Master programme in the field of physics and technology of controlled thermonuclear fusion is being finalised between AMU and MEPhI. It will facilitate administratively and in practice the exchange of students between the two programmes by recognising the successfully completed credit courses during the mobility and by awarding a double degree delivered by the host and the host universities. It also creates opportunities for lecturers of one programme to visit the other, for the benefit of the students. This agreement is fully consistent with the programme's policy of encouraging the students to study and work in an international environment, taking benefit of all the 
competences wherever they are, and presents also the advantage of widening the action radius of FUSION-EP to the other ITER members.

As the number of FUSION-EP associate partners grows this first agreement will be used as a starting point to set up similar agreements with other associated partners that can bring scientific and technological expertise and valuable multicultural experience to the FUSION-EP students. The mobility of students and staff will reinforce the existing network of the partners and bring new interactions thanks to the larger number of partners and the negotiations in view of associating new partners (in particular from the ITER members not yet represented in the consortium: India, Japan, Korea and the USA). The FUSION-EP programme will be a unique chance to set-up an international Master with a mandatory mobility and a multiple/joint diploma scheme offering a broad choice of specializations. Our ambition is to become the reference of the Masters in magnetic fusion in the world.

The experience of FUSION-EP can be extended to other high-tech fields. This is the main rationale for this:

- mixing with students from national programs, to promote cultural immersion, develop the student network and avoid forming elites disconnected from their national counterparts

- the distribution of students on different sites, provided that there are enough students.

- groupings in research institutions for common training events.

- adaptation of the composition of a consortium to the state of research as well as to teaching (for fusion, it is better to have a large consortium because it is a very multidisciplinary field; for other fields it could be smaller).

Fusion benefits from a well-structured European organization for research (this is also the case for high energy physics). Established links between research partners help to create the links necessary to create a HEl consortium.

The success of the FUSION-EP programme is largely due to the Erasmus Mundus joint master's degree (EM) scheme managed by EACEA and the EU [15]. This scheme, which promotes European higher education across Europe and worldwide, contributed scholarships and management costs for a total of 5 successive cohorts of students. FUSION-EP was awarded the funding at inception and, once again, five years later. This comfortable financial situation was instrumental to establish the programme at its partner universities, organising its administrative and financial management under the coordination of Ghent University and gathering experience in the organisation of student and scholar mobility. However, in spite of the resources brought about by the substantial number of self-funded students during the two periods, it became clear that long-term sustainability could not be guaranteed without external, perennial resources to replace the EU funding.

As a first step to sustainability, the consortium decided in September 2019 to entrust the programme coordination to Aix-Marseille University, geographically close to what has become the pivot point of fusion research: ITER. For many years the AMU research community has been linked with ITER IO directly, or in trilateral collaborations with CEA, through several collaborations on central physics and engineering questions. AMU and ITER IO have a memorandum of understanding on academic and scientific cooperation including the joint supervision of master theses. By tightening FUSION-EP's relationship with ITER IO, CEA-IRFM and the strong activity in fusion and plasma research and education on the Aix-Marseille site the FUSION-EP coordinating team aims to develop a "thermonuclear fusion higher education area" which could become a nexus of proposition and collaboration at the higher education level for magnetic fusion in Europe. It also aims at including higher education partners from all of the ITER Organisation members and raising the world-wide visibility, outreach and attractiveness of the programme. The purpose of the higher education area is to increase the global visibility of the programme to the level of ITER-related collaborations. While FUSION-EP students will remain evenly distributed among the core partners, the geographical, topical and professional proximity with ITER, along with the involvement of ITER IO as an associate partner, will allow an optimal alignment of the programme with the professional needs of the emerging nuclear fusion industry.

Thanks to this new momentum, FUSION-EP was awarded another EACEA grant starting on the next academic year. The funded period will be used to look for possible cost reductions, to improve the business model (e.g. evaluate more carefully the students' participation costs) and to search the necessary resources among industrial companies or consortia, institutional sources from the ITER members and governmental funding agencies such as the FuseNet Association [16]. with the help of the non-EU partners of the consortium. EUROfusion, the European consortium for the Development of Fusion energy which manages and funds European fusion research activities on behalf of EURATOM, has a special budget for education. Some FUSION-EP university partners use funds from the work package "Education" of EUROfusion to supplement the Erasmus Mundus Funding. In 2010 the FuseNet Association was founded to be a platform for the coordination of European fusion. FuseNet has, since 
the end of 2014, obtained financing from EUROfusion that can be used to cover some of the cost related to events such as mentioned in section 2. Although not directly a source of funding, it is important to note that the Erasmus Mundus brand accompanying the EMJMD funding is an important asset to the programme's attractiveness. It is expected that in the near future the EACEA allows the selected programmes to retain the brand even after the end of a funding period.

\section{Acknowledgements}

Frank Janssens, FUSION-EP manager at Ghent University (2006-2018), made invaluable contributions during his tenure. Alumni Ana Kostić and Milos Vlainić contributed the paragraph on the Serbian fusion education network (FOM). The authors salute the efforts of alumnus Mohamed Ezzat in Egypt and the FusionEPtalks team in attracting talented and inspired individuals to the field of fusion energy research.

\section{References}

[1] https://www.iter.org/

[2] https://www.euro-fusion.org/eurofusion/roadmap/

[3] Marques, M., Zapp, M. and Powell, J.J.W. 2020 Europeanizing Universities: Expanding and Consolidating Networks of the Erasmus Mundus Joint Master Degree Programme (2004-2017)". High. Educ. Policy https://doi.org/10.1057/s41307-020-00192-z

[4] Hillairet J 2020 https://iopscience.iop.org/article/10.1088/1361-6404/ab56df/pdf

[5] Stockel J, Cavalier J et al, to be submitted to European Journal of Physics

\section{[6] http://techtransfer.euro-fusion.eu/]}

[7] https://ec.europa.eu/energy/sites/ener/files/impact_of_the_iter_activities_in_the_eu-trinomics.pdf

[8] Komm M., Khodunov I., Cavalier J., et al 2019 Divertor impurity seeding experiments at the COMPASS tokamak, Nucl. Fusion 59106035

[9] Horacek J et al 2020 Scaling of L-mode heat flux for ITER and COMPASS-U divertors, based on five tokamaks Nucl. Fusion 60066016

[10] Adamek J, Tskhakaya D, Devitre A, Cavalier J et al 2020 On the transport of Edge Localized Mode filaments in the tokamak scrape-off layer to be published in Nucl. Fusion, 2020,https://doi.org/10.1088/1741-4326/ab9e14

[11] http://thefusioneerswiki.nfshost.com/FusioneersWiki/index.php/Main Page

[12] https://www.aprex-solutions.com/en/

[13] Grover O et al. 2016 Remote operation of the GOLEM tokamak for Fusion Fusion Engineering and Design 112 0920-3796. doi: http://dx.doi.org/10.1016/j.fusengdes.2016.05.009 
[15] https://eacea.ec.europa.eu/erasmus-plus

[16] https://www.fusenet.eu/ 